\title{
THE EFFECT OF THERAPEUTIC RADIO-PHOSPHORUS ON THE AFFINITY OF HAEMOGLOBIN FOR OXYGEN IN PATIENTS WITH POLYCYTHAEMIA VERA
}

BY

\author{
D. J. VALTIS AND A. C. KENNEDY \\ From the University Department of Medicine, the Royal Infirmary, Glasgow
}

(RECEIVED FOR PUBLICATION MARCH, 1954)

Detailed studies in polycythaemia vera (Berk, Burchinal, Wood, and Castle, 1948 ; Wasserman, Dobson, and Lawrence, 1949 ; Schwartz and Stats, 1949) have failed to show any abnormality which might support the theory that the disorder is due to anoxaemia, and there is a large measure of agreement that the condition results from a primary hyperplasia of the haemopoietic tissue of the body. Treatment has therefore been mainly directed at reducing this excessive activity, and radio-phosphorus has now become widely accepted (Lawrence, Berlin, and Huff, 1953) as a highly effective therapeutic agent. While there are numerous morphological studies (Lawrence et al., 1953) on the effect of radio-phosphorus upon the bone marrow and formed elements of the blood, there are no observations, as far as we are aware, on the effect of this form of radiation on the functional capacity of the red cell. We report here alterations in the affinity of haemoglobin for oxygen in patients with polycythaemia vera after the administration of radio-phosphorus.

\section{Material and Methods}

Six patients with polycythaemia vera were studied. The details of the cases are given in the accompanying table. In the two cases most intensively investigated (Cases 1 and 2) the circulating blood mass was reduced by repeated venesections before the administration of radiophosphorus $\left(\mathrm{P}^{32}\right)$. In these cases the preliminary

TABLE I

EFFECT OF RADIO-PHOSPHORUS ON THE OXYGEN DISSOCIATION IN POLYCYTHAEMIA VERA

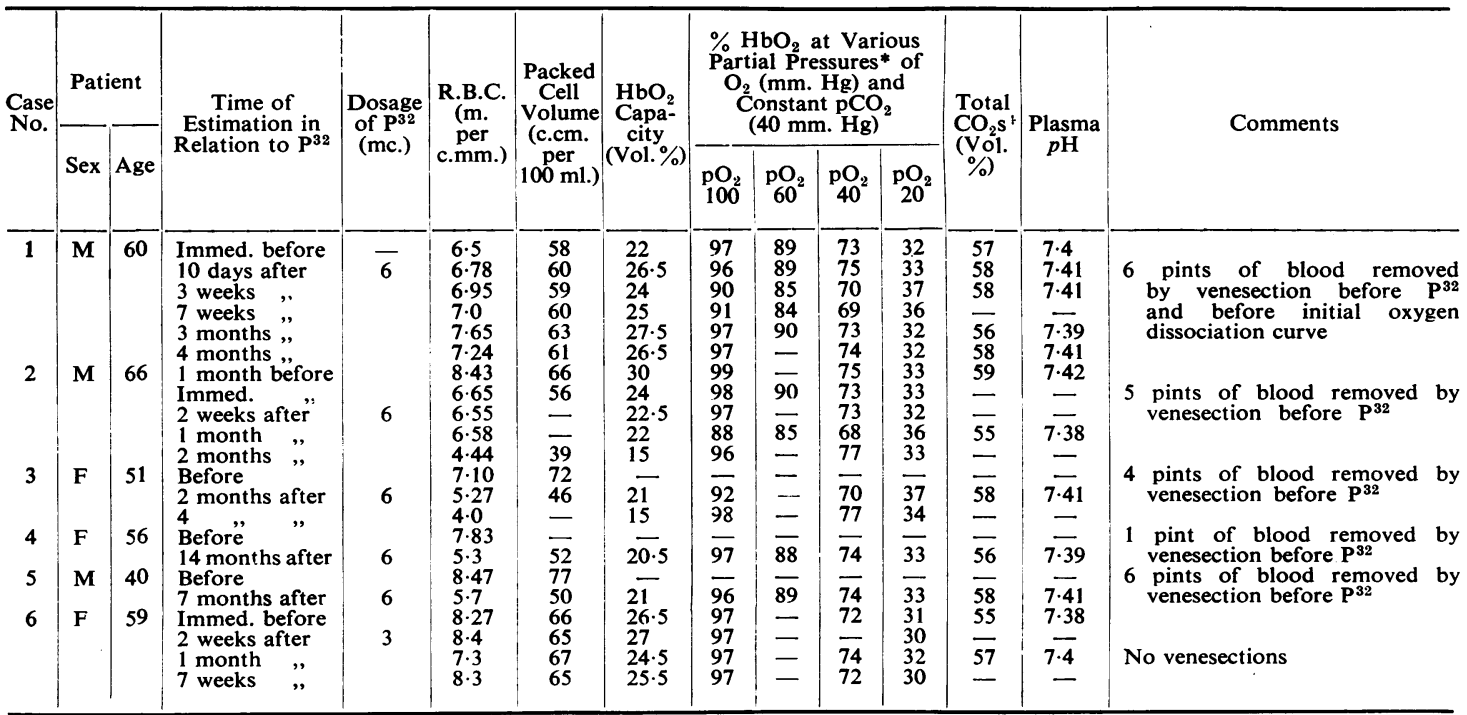

* The partial pressure of oxygen and carbon dioxide are expressed to the nearest whole figure.

$\dagger$ Total $\mathrm{CO}_{2} \mathrm{~s}=$ the total carbon dioxide of true plasma from oxygenated blood at a $\mathrm{CO}_{2}$ partial pressure of $40 \mathrm{~mm}$. $\mathrm{Hg}$. 
gas studies were performed after the venesections but before the administration of radio-phosphorus. Radio-phosphorus was given intravenously as $\mathrm{Na}_{2} \mathrm{HPO}_{4}$ in a dosage of 3 to 6 millicuries. The time relationship of the blood gas studies to the administration of the radio-phosphorus is indicated in the table.

The techniques used for the blood gas studies were as previously described (Valtis and Kennedy, 1954).

\section{Results}

The detailed results are given in Table $I$ and Fig. 1.

All the oxygen dissociation curves performed before radio-phosphorus was given were normal (Cases 1, 2, and 6). Normal oxygen dissociation

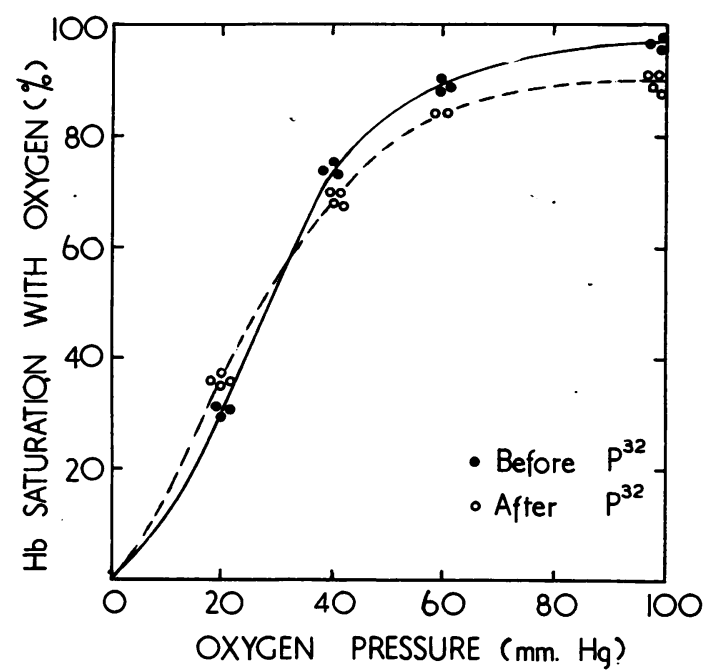

Fig. 1.-Position of the oxygen dissociation curve in three cases of polycythaemia vera before and one to two months after $\mathbf{P}^{32}$.

curves were also obtained in the two patients (Cases 4 and 5) to whom a dose of radio-phosphorus had been given several months before the present study.

In contrast to these findings, the oxygen dissociation curves were abnormal in Cases 1 and 2 one to two months after the administration of 6 millicuries of radio-phosphorus. A similarly abnormal curve was also obtained two months after the administration of 6 millicuries of radiophosphorus in Case 3 ; unfortunately, in this case, a curve was not performed before radio-phosphorus was given. The curves obtained in these three cases, during the one to two months after radio-phosphorus therapy, crossed the normal curve at approximately $30 \mathrm{~mm}$. $\mathrm{Hg}$ partial pressure of oxygen, the upper part of the curve being lower than normal and the lower part higher than normal. Oxygen dissociation curves performed in these patients more than two months after radio-phosphorus therapy were normal.

In Case 6, only a small dose, 3 millicuries, of radio-phosphorus was given; no alteration in the oxygen dissociation curve was observed during the subsequent two months.

It will be seen from the table that a satisfactory therapeutic depression of the red cell level followed radio-phosphorus therapy in Cases 2, 3, 4, and 5 .

\section{Discussion}

Our results show that in three cases of poly. cythaemia vera which received 6 millicuries of radio-phosphorus the oxygen dissociation curve was temporarily altered, the change being evident in the period between one and two months after radio-phosphorus. No alteration was noted during this period in the patient who received 3 millicuries of radio-phosphorus or in the two cases in which blood gas studies were performed for the first time several months after radiophosphorus.

The alteration of the oxygen dissociation curve observed was not the parallel alteration in position, which we have observed on numerous occasions (Valtis and Kennedy, 1954), resulting from changes in $p \mathrm{H}$ or electrolytes (Barcroft, 1928), from alterations in the water content of the red cell (Henderson, 1928), or from anaemia (Richards and Strauss, 1927). The fundamental work of Barcroft suggests that changes in the shape of the curve, of the type that we have observed, indicate that there is some alteration in the basic elements of haemoglobin. The fact that the alteration of the oxygen dissociation curve is not present until some weeks after the administration of radio-phosphorus suggests that it may be related in some way to internal radiation from radio-phosphorus on the red cell precursors in the bone marrow. The therapeutic activity of radio-phosphorus, in the form $\mathrm{Na}_{2} \mathrm{HPO}_{4}$, appears to be due to its synthesis into important cell constituents, including ribo- and thymo-nucleic acids of multiplying cells (Mitchell, 1951), and the importance of these substances in the metabolism of factors necessary for red cell maturation is also well known (Vilter, Horrigan, Mueller, Jarrold, Vilter, Hawkins, and Seaman, 1950). It is conceivable that as a result of this action there is some alteration in the synthesis of haemoglobin in the red cells produced under the influence of internal radiation which could be responsible for the abnormality we have observed. 
It is interesting to speculate whether the effect on the oxygen dissociation curve is peculiar to the radiation produced by radio-phosphorus, or whether it would also be produced by $x$-ray radiation, particularly of the skeleton. As far as we are aware, there are no studies which have been published in this field.

It is unlikely that the sulphur products resulting from the decay of radio-phosphorus are the cause of the alterations in the oxygen dissociation curve -since the quantities involved are very small and, moreover, $50 \%$ of the administered radio-phosphorus is excreted or decayed within 14 days: after six weeks only about $10 \%$ of the substance remains (Hevesy, 1948).

As a result of the alteration in the oxygen dissociation curve which we have demonstrated, the blood of the patient will, for a period, take up oxygen less readily in the lungs and release oxygen less readily to the tissues. The magnitude of the changes is not sufficient, however, to affect significantly the oxygenation of the tissues, particularly if, as in the patients we have studied, the haemoglobin level is normal or even above normal.

\section{Summary}

The oxygen transport by the blood in polycythaemia vera has been studied before and after the administration of radio-phosphorus. A temporary alteration, apparent between one and two months after radio-phosphorus, in the oxygen dissociation curve was observed; the affinity of haemoglobin for oxygen at high oxygen partial pressures (greater than $60 \mathrm{~mm}$. $\mathrm{Hg}$ ) was decreased and the affinity at low oxygen partial pressures (less than $40 \mathrm{~mm}$. $\mathrm{Hg}$ ) was increased. These changes indicate a reduced saturation of haemoglobin with oxygen in the lungs and a reduced release of oxygen to the tissues.

The causation of the changes is briefly discussed.

We wish to express our thanks to Professor L. J. Davis for his advice and encouragement throughout this study; the radio-phosphorus was administered by Dr. E. M. McGirr. One of us (D.J.V.) was enabled to undertake this work by scholarships from the E.C.A. for Greece and from the University of Thessalonica. Much of the cost of apparatus and materials was provided by the Rankin Fund of the University of Glasgow.

\section{RFFERENCES}

Barcroft, J. (1928). The Respiratory Function of the Blood, Pt. II. Haemoglobin. University Press, Cambridge.

Berk, L., Burchenal, J. H., Wond, T., and Castle, W. B. (1948) Proc. Soc. exp. Biol., N.Y., 69, 316.

Henderson, L. J. (1928). Blood. Yale University Press, New Haven, Conn.

Hevesy, G. (1948). Radioactive Indicators. Interscience, New York. Lawrence, J. H., Berlin, N. I., and Huff, R. L. (1953). Medicine, Baltimore, 32, 323.

Mitchell, J. S. (1951). Brit. med. J., 2, 747.

Richards, D. W., Jr., and Strauss, M. L. (1927). J. clin. Invest., 4, 105. Schwartz, B. M., and Stats, D. (1949). Ibid., 28, 736.

Valtis, D. J., and Kennedy, A. C. (1954). Lancet, 1, 119.

Vilter, R. W., Horrigan, D., Mueller, J. F. Jarrold, T., Vilter, C. F., Hawkins, V., and Seaman, A. (1950). Blood, 5, 695.

Wasserman, L. R., Dobson, R. L., and Lawrence, J. H. (1949). J. clin. Invest., $28,60$. 